\title{
Porcine epidemic diarrhea virus $M$ protein blocks cell cycle progression at S-phase and its subcellular localization in the porcine intestinal epithelial cells
}

\author{
X. G. XU*, H. L. ZHANG*, Q. ZHANG, J. DONG, Y. HUANG, D. W. TONG*
}

College of Veterinary Medicine, Northwest A\&F University, Yangling, Shaanxi 712100, P. R. China

Received October 6, 2014; revised April 9, 2015; accepted August 11, 2015

\begin{abstract}
Summary. - Porcine epidemic diarrhea (PED) caused by virulent strains of porcine epidemic diarrhea virus (PEDV) is a highly contagious enteric disease of swine characterized by severe enteritis, vomiting, and watery diarrhea. This study investigates the subcellular localization and function of PEDV M protein through examination of its effects on cell growth, cell cycle progression, and interleukin 8 (IL-8) expression. Our results revealed that the PEDV M protein is localized throughout the cytoplasm. The M protein altered swine intestinal epithelial cell line (IEC) growth and induced cell cycle arrest at the S-phase via the cyclin A pathway. The S-phase arrest is associated with a decrease in level of cyclin A. Furthermore, our results revealed that the $\mathrm{M}$ protein of PEDV does not induce endoplasmic reticulum (ER) stress and does not activate NF- $\kappa \mathrm{B}$ which is responsible for IL-8 and Bcl-2 expression. This is the first report to demonstrate that the PEDV M protein is localized in the whole cell and induces cell cycle arrest at the S-phase. This study provides novel findings in the function of M proteins of PEDV.
\end{abstract}

Keywords: PEDV M protein; S-phase; cyclin A; subcellular localization; IL-8

\section{Introduction}

Porcine epidemic diarrhea virus (PEDV) causes severe enteritis, vomiting, and watery diarrhea and results in high mortality in piglets (Ducatelle et al., 1981). PEDV is an enveloped virus possessing an approximately $28 \mathrm{~kb}$, positivesense, single-stranded RNA genome with a 5 ' cap and a $3^{\prime}$ polyadenylated tail (Song and Park, 2012; Wang et al., 2012). The genome consists of seven open reading frames (ORFs) that encode four structural proteins and three non-structural proteins. The genome is arranged in the order: 5 '-replicase (1a/1b)-S-ORF3-E-M-N-3' (Bridgen et al., 1998; Egberink

*Corresponding author. E-mail address: dwtong@nwsuaf.edu.cn; phone: +86-29-8709-1622. "Both two authors contributed equally to this work.

Abbreviations: $\mathrm{ER}=$ endoplasmic reticulum; $\mathrm{IEC}=$ intestinal epithelial cell line; IL-8 = interleukin 8; $\mathrm{M}=$ membrane; ORFs = open reading frames; $\mathrm{PED}=$ porcine epidemic diarrhea; $\mathrm{PEDV}=\mathrm{PED}$ virus; UPR = unfolded protein response et al., 1988; Kocherhans et al., 2001). Genes for the major structural proteins, spikes (S, 180-220 K), membrane (M, 27-32 K), nucleocapsid (N, $58 \mathrm{~K}$ ) and small membrane protein $(\mathrm{E}, 7 \mathrm{~K})$ are located downstream of the polymerase gene (Locker et al., 1992; Yeo et al., 2003).

PEDV $M$ protein not only plays an important role in the viral assembly process but also induces antibodies that neutralize the virus in the presence of its complement (Song and Park, 2012). The M protein plays an important role in a-IFN induction (Laude et al., 1992). One of the most essential phases during cell cycle is the $S$ phase because this phase provides a cellular environment that is beneficial for viral replication. Recently, it was also reported that G2-M phase arrest of the cell cycle is beneficial for viral replication (Chulu et al., 2010; Liu et al., 2005). To date, no data show the subcellular localization of PEDV M protein and its effects on cell growth and cell cycle progression. The intestinal epithelial cells are the PEDV target cells, while the epithelial cells in the gut serve as a physical barrier which restricts the movement of components and the movement of potentially harmful microorganisms between the lumen and the under- 
lying mucosa (Schierack et al., 2005). Under conditions of ER stress, the unfolded protein response (UPR) can initiate inflammation in mammalian cells and these responses are thought to be essential in the pathogenesis of inflammatory diseases (Todd et al., 2008; Zhang and Kaufman, 2008).

The aim of this study was to demonstrate the subcellular localization of PEDV M protein and clarify its effects in cell growth and cell cycle progression. The results revealed that the expression of PEDV M protein causes the cell growth retardation in intestinal epithelial cell line (IEC) and blocks cell cycle progression at S-phase. The cell cycle effect is associated with downregulation of cyclin A. Furthermore, our results revealed that PEDV M protein is localized in the whole cell. Under conditions of ER stress, the UPR can initiate inflammation in mammalian cells and these responses are essential in the pathogenesis of inflammatory diseases (Todd et al., 2008; Zhang and Kaufman, 2008). IL-8 is a pro-inflammatory neutrophil chemotactic factor that plays an important role in the promotion of cell survival signaling (Luppi et al., 2007; Waugh and Wilson, 2008). However, no effect on the IL-8 expression and NF- $\kappa$ B activation in IEC by PEDV M protein was observed. Furthermore, the cells expressing PEDV M protein also show no change in the $\mathrm{Bcl}-2$ expression. These results have potentially important implications in understanding the molecular mechanisms of pathogenesis for this economically important porcine disease. To our knowledge, this is the first report regarding the biological functions of the $M$ protein of PEDV in IEC.

\section{Materials and Methods}

Vectors and cells. The pEGFP-N1 eukaryotic expression vector was obtained from ClonTech Co. (Japan) and E. coli DH5a used for cloning were purchased from Tiangen Biotech Co. (China). In the present study, the Shaanxi strain of PEDV was isolated from intestinal tract contents of PEDV infected piglets in Shaanxi province of China as described previously (Honglei et al., 2012). The established swine IEC lines were kindly provided by Prof. Yan-Ming Zhang, College of veterinary medicine, Northwest A \& F University and cultured as described previously (Jing et al., 2010). Briefly, IEC were grown in Dulbecco's modified eagle medium (DMEM) (Gibco BRL) supplemented with $10 \%$ heat-inactivated calf serum (Gibco $\mathrm{BRL}), 100 \mathrm{IU} / \mathrm{ml}$ of penicillin and $100 \mu \mathrm{g} / \mathrm{ml}$ of streptomycin, at $37^{\circ} \mathrm{C}$ in a $5 \% \mathrm{CO}_{2}$ atmosphere incubator.

Reagents and antibodies. The MG132 proteasome inhibitor was purchased from Calbiochem and the nuclear staining dye Hoechst 33342 and ER-Tracker ${ }^{\text {Txx }}$ Red probe were obtained from Invitrogen. Mouse monoclonal antibodies against cyclin A, GRP78 and $\beta$-actin were from Santa Cruz Biotechnology. Porcine anti-PEDV polyclonal antibody was kindly provided by Dr. Faxing Wu, China animal health and epidemiology center, China. A mouse anti-GFP monoclonal antibody was purchased from Millipore. Horseradish peroxidase (HRP)-conjugated secondary antibody was ordered from Pierce. Cy3-conjugated rabbit anti-pig MAb was purchased from SiRuiKe Biotechnology Co. (China).

Construction of recombinant plasmid and establishment of stable cell lines expressing GFP-M and GFP protein. The primers were designed according to the nucleotide sequences of PEDV CV777 strain (GenBank Acc. No. AF353511.1). The sequences of primers used to amplify the M gene of PEDV are as follows: forward primer (PEDV-XhoI), 5'-CC GCTCGAGATGTCTAACGGTT CTATT-3' (25682-25699 nt) and reverse primer (PEDV-EcoRI), 5'-CCGGAATTCCGACTAAATGAAGCAC-3' (26345-26359 nt). The restriction sites are underlined. The PCR products were cloned into the corresponding sites in the pEGFP-N1 expression vector. The recombinant plasmid was verified by enzyme digestion and DNA sequencing. The resultant recombinant plasmid was named as pEGFP-M. IEC cells were seeded in to 6-well dishes $24 \mathrm{hr}$ before transfection (up to $70-80 \%$ confluence). Cells were transfected with pEGFP-M and pEGFP-N1 control vector using Lipofectamine 2000 (Invitrogen) and maintained (up to $80-90 \%$ confluence) in selection media containing $1200 \mu \mathrm{g} / \mathrm{ml}$ of G418 for two weeks. When all control cells showed evidence of death in the presence of the selection agent, cells transfected with pEGFP-M and pEGFP-N1 were cultured for two additional weeks in medium which contained $600 \mu \mathrm{g} / \mathrm{ml}$ of G418. The cell lines stably expressing either GFP or GFP-M fusion protein were used for subsequent studies.

Confocal microscopy. To investigate the expression and subcellular localization of the M protein of PEDV, cell lines stably expressing GFP-M protein and control cells (GFP and untransfected IEC cells) were grown on glass bottom dishes $(35 \mathrm{~mm})$ and washed with Hank's balanced salt solution (HBSS). These were subsequently incubated with Hoechst 33342 at $37^{\circ} \mathrm{C}$ for $10 \mathrm{~min}$, and then washed twice with HBSS. Cells were then incubated with ER-Tracker Red probe (Invitrogen) at $37^{\circ} \mathrm{C}$ for $25 \mathrm{~min}$ and washed with HBSS twice. Images were viewed by laser confocal scanning microscopy (Zeiss). The other sets of cells were used to examine the expression and subcellular localization of PEDV M protein. The cells were fixed by methanol/acetone $(1: 1)$ for $5 \mathrm{~min}$ at $-20^{\circ} \mathrm{C}$, rinsed with HBSS, and blocked with $2 \%$ bovine serum albumin for $30 \mathrm{~min}$ at $37^{\circ} \mathrm{C}$. The cells were then incubated with an anti-PEDV antibody (1:100 dilutions) for $1 \mathrm{hr}$ at $37^{\circ} \mathrm{C}$, followed by three washes with HBSS. The cells were then incubated with the secondary antibody (Cy3-conjugated rabbit anti-pig MAb, 1:500 dilution, SiRuiKe Biotechnology Co) for $1 \mathrm{hr}$ at $37^{\circ} \mathrm{C}$, followed by three washes with HBSS. The control cells (GFP and untransfected IEC cells) were treated the same way. Protein localization was visualized using a confocal microscope (Zeiss).

Western blot analysis. Cells were collected and washed with ice-cold PBS and then treated with ice-cold RIPA lysis buffer with $1 \mathrm{mmol} / \mathrm{l}$ phenylmethyl sulfonylfluoride (PMSF). Cell lysates were centrifuged at $12,000 \times \mathrm{g}$ at $4^{\circ} \mathrm{C}$ for $10 \mathrm{~min}$. Protein concentrations were measured using BCA protein assay reagent (Pierce). Equivalent amounts of proteins were loaded and 
electrophoresed on $12 \%$ SDS-PAGE electrophoresis. Proteins were then transferred to the polyvinylidene difluoride (PVDF) membrane (Millipore). The membrane was blocked with $5 \%$ nonfat dry milk at room temperature for $1 \mathrm{hr}$, and then incubated with respective primary antibodies overnight at $4^{\circ} \mathrm{C}$, followed by HRP-conjugated secondary antibodies at room temperature for $1 \mathrm{hr}$. The signal was detected by enhanced chemiluminescence (ECL) reagents (Pierce).

Cell proliferation assay. The MTT assay was carried out to determine the growth properties of PEDV M-expressing cells and control cells as described previously (Xu et al., 2013b). Briefly, cells were seeded in 96-well culture plates at a concentration of $2 \times 10^{3}$ cells in $200 \mu \mathrm{l}$ culture medium in each well. After incubation at $37^{\circ} \mathrm{C}$ with $5 \% \mathrm{CO}_{2}$ for $24 \mathrm{hr}, 48 \mathrm{hr}, 72 \mathrm{hr}$ and $96 \mathrm{hr}$, the culture medium was carefully replaced with $200 \mu \mathrm{l}$ of a fresh medium without disturbing the cells. Twenty microlitres of 3-(4, 5-dimethylthiazol-2-yl) 2, 5-diphenyl-tetrazolium bromide (MTT, $5 \mathrm{mg} / \mathrm{ml}$ ) (Sigma) reagent was added to each well and incubated in a $\mathrm{CO}_{2}$ incubator at $37^{\circ} \mathrm{C}$ for $4 \mathrm{hr}$. After $4 \mathrm{hr}$ incubation, the reactions were stopped by addition of $100 \mu$ of DMSO into each well. The plates were read at an absorbance wavelength of $490 \mathrm{~nm}$ using a microplate (Bio-Rad) at appropriate time intervals.

Cell cycle analysis by flow cytometry. The cell cycle was examined by using propidium iodide staining as described previously (Tang et al., 2010; Xu et al., 2013a,b). Briefly, approximately $2 \times 10^{6}$ of cells stably expressing M protein and control cells were treated with trypsin, washed with PBS twice, resuspended in $75 \%$ ethanol and fixed at $4^{\circ} \mathrm{C}$ for 3 days. Cells were washed with PBS and resuspended in PBS containing $20 \mu \mathrm{g} / \mathrm{ml}$ of RNase A and $50 \mu \mathrm{g} / \mathrm{ml}$ of propidium iodid and incubated at $4^{\circ} \mathrm{C}$ for $30 \mathrm{~min}$ in the dark. Finally, the nuclear DNA content was measured by a Coulter Epics XL flow cytometer (Beckman).

Reverse transcription and real-time quantitative polymerase chain reaction ( $q P C R$ ). Total RNA was extracted from cells using Trizol reagent (Invitrogen) according to the manufacturer's instructions. The reverse transcription was carried out with M-MLV reverse transcriptase, oligo (dT) 18 primers and $2 \mu \mathrm{g}$ of total RNA. The expression of genes was quantified by real-time qPCR as described in previous protocols (Ke et al., 2006; Xu et al., 2013a). The primers for qPCR in this study are shown in Table 1. Real-time qPCR was carried out in a total of $25 \mu$ containing SYBR Premix Ex TaqTM II (Takara), sense and anti-sense primers $(0.4 \mu \mathrm{mol} / \mathrm{l})$ and target cDNA ( $4 \mathrm{ng}$ ). The cycling conditions were $95^{\circ} \mathrm{C}$ for $5 \mathrm{~min}$, followed by 40 cycles of $95^{\circ} \mathrm{C}$ for $5 \mathrm{sec}, 60^{\circ} \mathrm{C}$ for $30 \mathrm{sec}$. A negative control was used in each run and the specificity of amplification reaction was examined by melting curve (Tm value) analysis. The individual samples were normalized for genome equivalents using the respective CT value for the porcine housekeeping gene ( $\beta$-actin). The relative quantification of gene expression was analyzed by the two-ddCt method as described previously (Livak and Schmittgen, 2001).

Detection of NF- $\kappa B$ activity. To determine the NF- $\kappa$ B activity caused by GFP and GFP-M protein in the established cell lines, the level of NF- $\kappa$ B activity was examined by NF- $\kappa B$ p 65 TransAM kit (Active Motif) according to the manufacturer's instructions. Briefly, cell nuclear extracts were prepared by the Nuclear extract kit (KeyGEN, China) and protein concentrations were determined using the BCA protein assay reagent. A total of $50 \mu \mathrm{g}$ of protein lysates were incubated in ELISA wells pre-coated with the oligonucleotide motif recognized by active p65. The NF- $\mathrm{kB}$ p 65 was then detected with a specific antibody against $\mathrm{p} 65$, followed by a horseradish peroxidase (HRP)-conjugated secondary antibody. The colorimetric reaction was measured at $450 \mathrm{~nm}$.

ELISA. The cells stably expressing PEDV M protein and control cells were grown in 24-well plates at a density of $1 \times 10^{5} \mathrm{cells} / \mathrm{ml}$ in DMEM with $10 \%$ calf serum and cultured for $48 \mathrm{hr}$. In this study, MG132 that was found to block IL-8 expression was added after $24 \mathrm{hr}$ (Matsuo et al., 2009). The culture medium was then collected and centrifuged at $1000 \times \mathrm{g}$ for $5 \mathrm{~min}$ to remove debris. The supernatants were stored at $-80^{\circ} \mathrm{C}$ until use. The concentration of IL-8 was measured using a swine IL- 8 ELISA kit according to the manufacturer's instructions (Invitrogen).

Statistical analysis. All data were shown as the means \pm SD from three independent experiments in triplicate. Results were analyzed by Student's $t$-test. $P$ value less than 0.05 were considered to be statistically significant.

\section{Results}

\section{PEDV M protein expression in IEC}

The M gene of PEDV was subcloned into the vector pEGFP-N1 and then transformed into Escherichia coli

Table 1. The primers for real-time $\mathrm{qPCR}$

\begin{tabular}{lllll}
\hline Gene & Forward primer $\left(\mathbf{5}^{\prime}-\mathbf{3}^{\prime}\right)$ & Reverse primer (5'-3') & $\begin{array}{c}\text { Product } \\
\text { (bp) }\end{array}$ & Acc. No. \\
\hline Cyclin A & AAGTTTGATAGATGCTGACCCGTAC & GCTGTGGTGCTCTGAGGTAGGT & 194 & GQ265874 \\
GRP78 & AATGGCCGTGTGGAGATCA & GAGCTGGTTCTTGGCTGCAT & 114 & X92446 \\
IL-8 & CTGGCTGTTGCCTTCTTG & TCGTGGAATGCGTATTTATG & 113 & M86923 \\
Bcl-2 & TTGTGGCCTTCTTTGAGTTCG & CTACCCAGCCTCCGTTATCC & 150 & XM_003121700.1 \\
$\beta$-actin & GGACTTCGAGCAGGAGATGG & AGGAAGGAGGGCTGGAAGAG & 138 & XM_003124280.1 \\
\hline
\end{tabular}


(a)

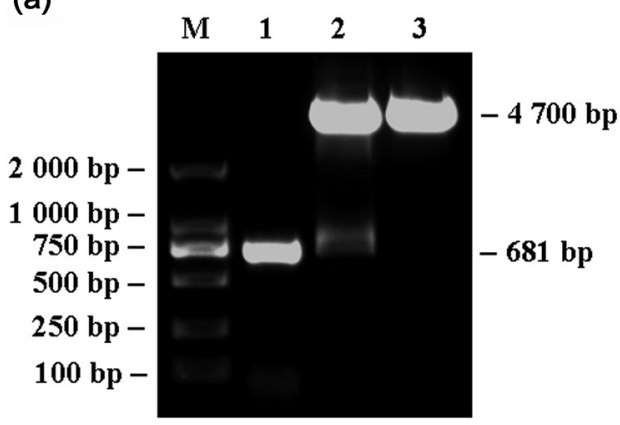

(b)

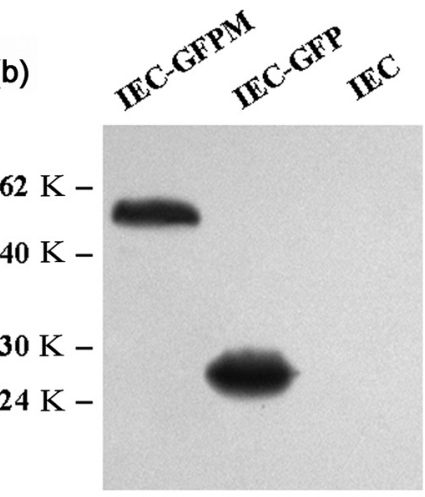

Fig. 1

Analysis of recombinant plasmid pEGFP-N1-M and GFP-M fusion protein expression

(a) Double restriction enzyme digestion profiles of recombinant plasmid pEGFP-N1-M. Lane M: DNA marker; lane 1: PCR products of PEDV M gene; lane 2: pEGFP-N1-M digested with restriction enzymes XhoI and EcoRI; lane 3: pEGFP-N1 digested with restriction enzymes XhoI and EcoRI. (b) Western blot analyses of GFP-M fusion protein and GFP in IEC cells and control IEC cells.

DH5a. Transformants were grown on LB plates with appropriate selective antibiotics. As shown in Fig. 1a, the recombinant plasmid pEGFP-N1-M was digested with both XhoI and EcoRI restriction enzymes. The size of the digested DNA bands is consistent with the PCR products of PEDV M gene. According to Western blot analysis, a molecular mass of approximate $55 \mathrm{~K}$ protein was present in the protein extracts from cells transfected with the pEGFP-N1-M plasmid (Fig. 1b). Since the molecular mass of GFP is known to be approximately $27 \mathrm{~K}$, this is in agreement with the predicted size of $\mathrm{M}$ protein which is approximately $28 \mathrm{~K}$. No signal was detected from the negative IEC control cells.

\section{Subcellular localization of the PEDV M protein}

The subcellular localization of the M protein of PEDV was examined by confocal fluorescence microscopy. Our results revealed that GFP alone and GFP-M protein are localized in the whole cell (Fig. 2a). To further investigate the subcellular localization of PEDV M protein, cells subjected to immunofluorescence labeling were observed by confocal fluorescence microscopy. As shown in Fig. 2b, there were no proteins detectable by the anti-PEDV antibody in the control cells (GFP and untransfected IEC cells). However, the GFP-M protein labeled by anti-PEDV antibody was detected in the whole cell. These results suggest that PEDV $\mathrm{M}$ protein is localized in the whole cell.

\section{Effect of PEDV M protein on cell proliferation}

Compared to pEGFP-N1 transfected and untransfected control cells, cells expressing M protein had much slower cell cycle, leading to a significant decrease in cell number after a certain period of time. Cell proliferation analysis of the M-expressing cells was measured by MTT assay, showing approximately 30\% decrease over a time course of 96 hr (Fig. 3).

\section{PEDV M protein expression induces cell cycle arrest in} the S-phase

To investigate whether the growth effect of M protein expressing cells was due to the arrest of the cell cycle at a certain phase of the cell cycle progression, flow cytometric analysis was performed based on the DNA content in nuclei stained with propidium iodid. The proportions of G0/G1 phase, S-phase and G2/M phases for the control cells were $71.4 \%, 21.7 \%$ and $6.8 \%$, respectively. For IEC expressing GFP, the proportions of the phases of cell cycle were for G0/G1: $76.5 \%$, S-phase: $16.5 \%$, and G2/M: $6.8 \%$, respectively whereas for GFP-M-expressing IEC, the proportions were for G0/G1: 63\%, S-phase: $29.9 \%$ and G2/M: 7.1\%, respectively (Fig. 4a). The histograms were quantitatively analyzed to determine the percentage of cells in each of the G0/G1, S, and G2/M phases (Fig. 4b), where G0/G1 phase cells had 2N DNA content and G2/M phase cells showed 4N DNA content. These data strongly suggest that $\mathrm{M}$ protein induces cell cycle arrest in the S-phase and prevents GFP-M expressing cells from entering the G2/M phase. The results show that, relative to control cells, expression of PEDV M protein leads to a significant increase of number of cells in the S-phase of cell cycle accompanied by a decrease in cell number in the G0/G1 phase of cell cycle. In conclusion, these results revealed that the M protein of PEDV induces cell cycle arrest in the S-phase of cell cycle. 


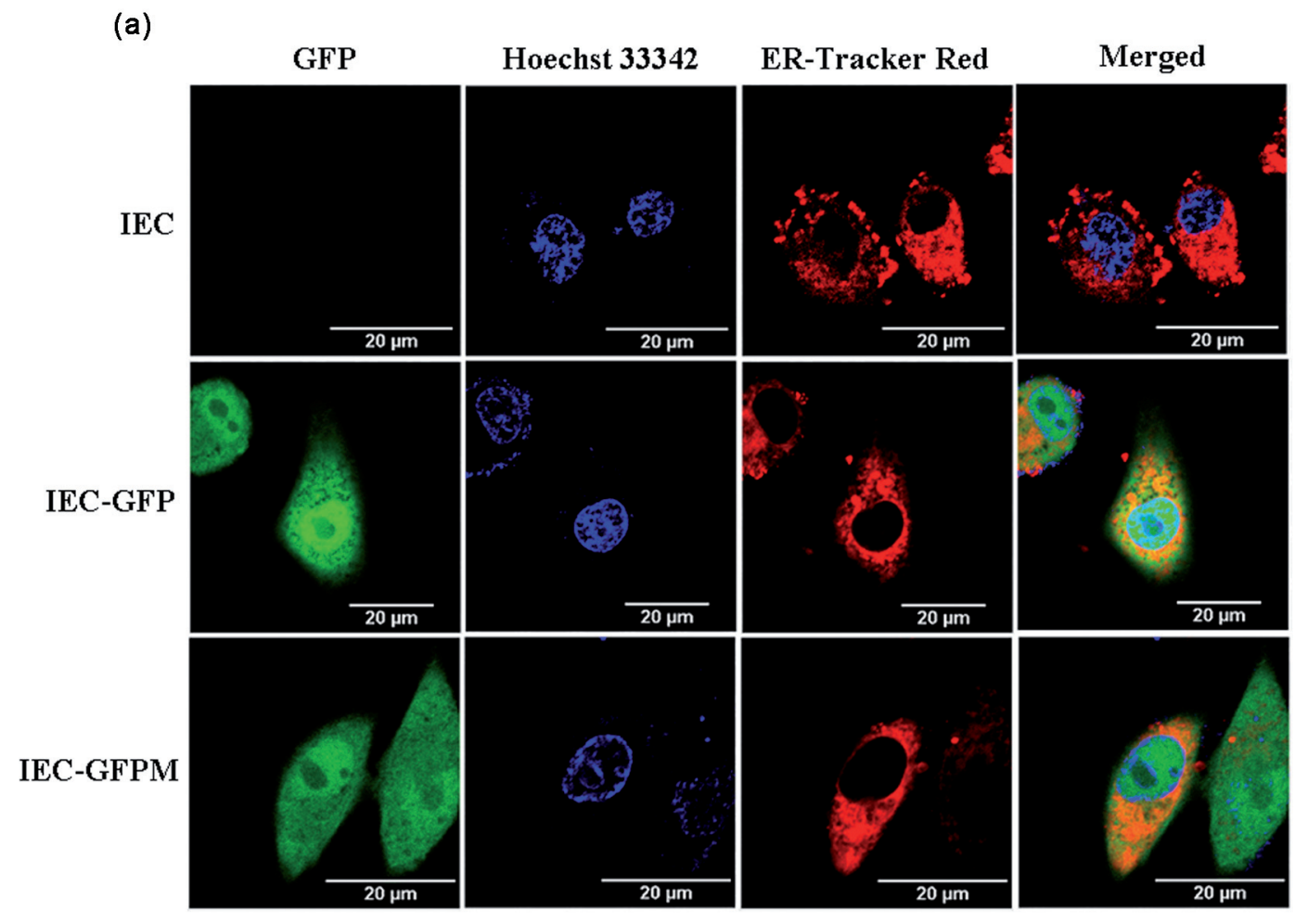

(b)

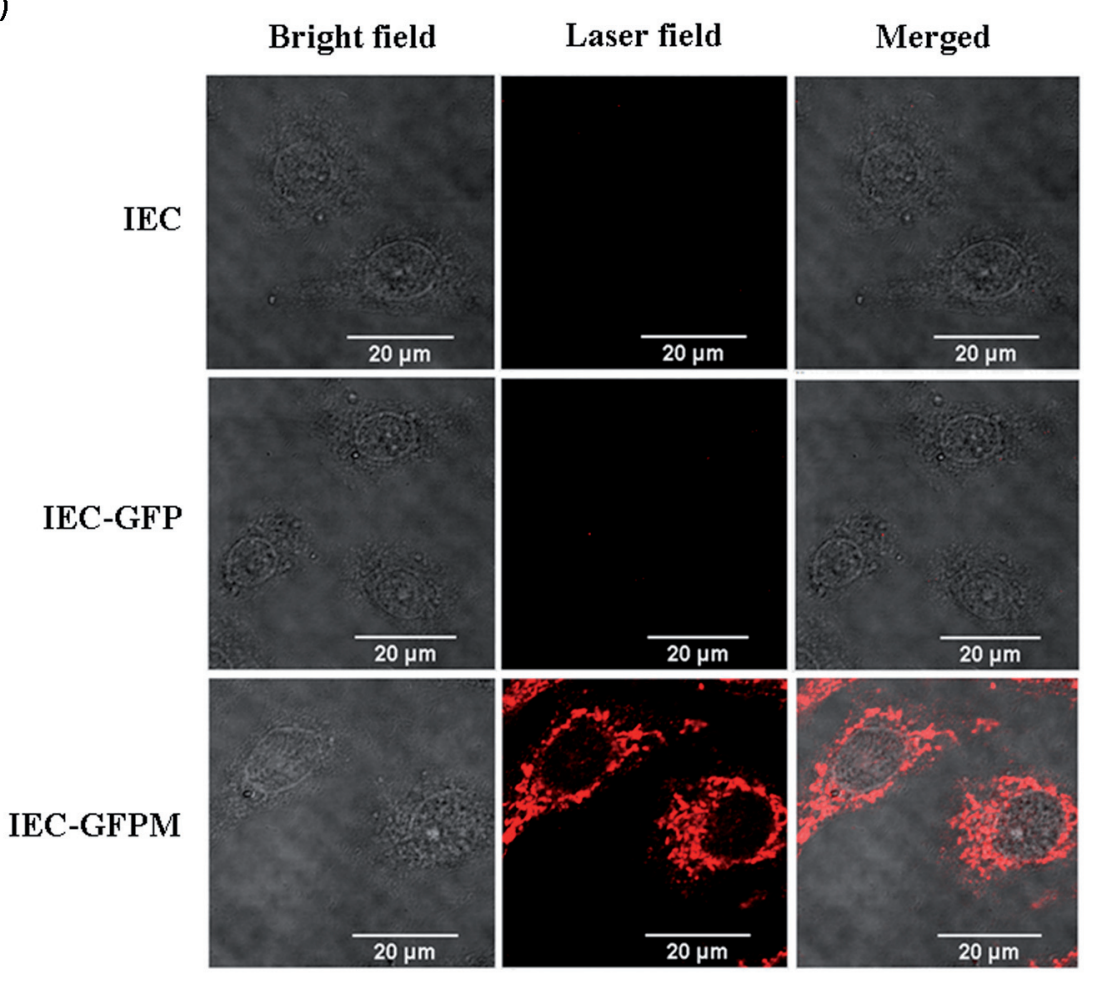

Fig. 2

Subcellular localization of GFP-M fusion protein in IEC observed by confocal microscopy Immunofluorescence of IEC control cells and GFP and GFP-M transfected cells. (a) Cells were stained with Hoechst 33342 and ER-Tracker ${ }^{\mathrm{mw}}$ Red. (b) Cells were detected by an anti-PEDV antibody. Bar $=20 \mu \mathrm{m}$. 
Cell cycle arrest induction is caused by the cyclin A downregulation

Cyclin A is the key regulator that mediates cell cycle progression from the $\mathrm{S}$ phase to the G2/M phase. Having shown that PEDV M protein induces cell cycle arrest at Sphase of cell cycle, we next wanted to elucidate the underlying mechanism of $\mathrm{M}$-induced $\mathrm{S}$ phase cell cycle arrest. The cyclin A protein level in transfected cells and control cells was examined by Western blot analyses. As shown in Fig. 5a, the expression level of cyclin A was significantly decreased in cells stably expressing the M protein compared to control cells. This indicates that PEDV M protein, rather than GFP, blocks cell cycle progression at the S phase of cell cycle. To support this finding, qRT-PCR was employed to detect the cyclin A mRNA level. The results showed that the mRNA level of cyclin A in the GFP-M expressing cells was significantly lower than in control cells (Fig. 5b), suggesting that induction of cell cycle arrest in the $\mathrm{S}$ phase by the $\mathrm{M}$ protein is associated with a decrease in cyclin A transcription.

PEDV M protein does not induce ER stress nor NF- $\kappa B$ activation

Western blot analyses was used to examine the expression level of glucose regulated protein (GRP78), a well characterized ER chaperone protein that is a marker of ER

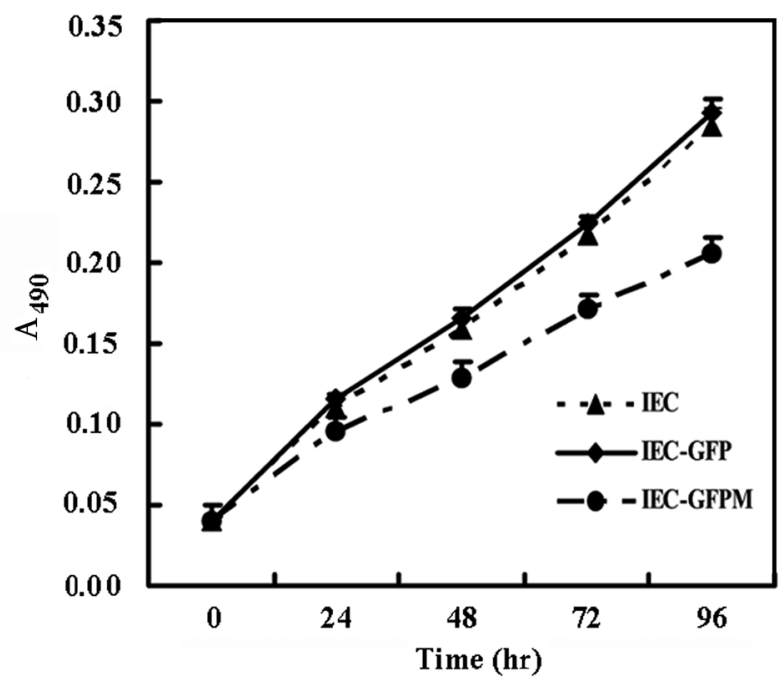

Fig. 3

Cell proliferation assays of the $M$ protein expressing cells The MTT assay was used to measure proliferation of $3 \times 10^{3}$ cells expressing GFP and GFP-M and control IEC cells over time. Each data set represents the mean \pm SD of six replicates.

stress (Hong, 2005; Li et al., 2008; Quinones et al., 2008). In the present study, the expression level of GRP78 was not altered in the cells that express $M$ protein nor in control

(a)

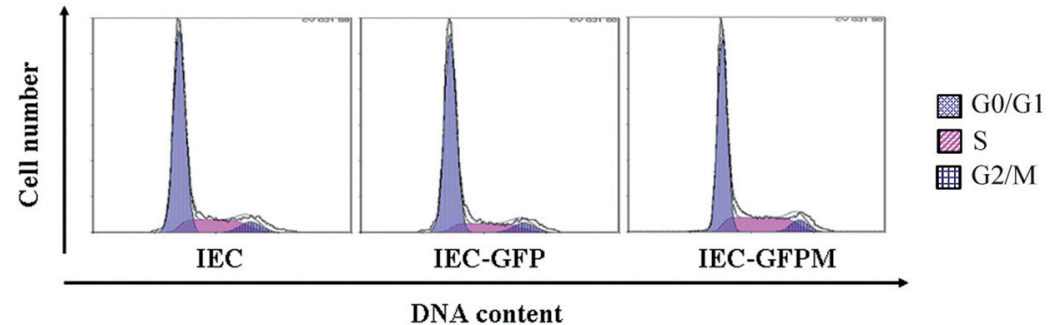

(b)

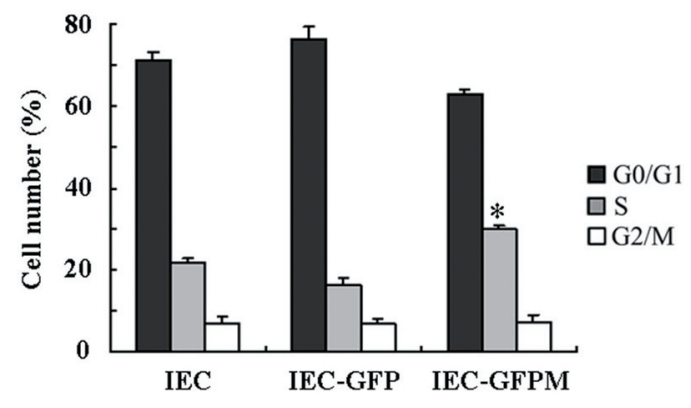

Fig. 4

Analysis of cell cycle stages of cells expressing PEDV M by flow cytometry

(a) Flow cytometry analysis of cells by propidium iodide staining. (b) The percentage of cells in each phase of the cell cycle from flow cytometry data. The results are mean \pm SD from three independent experiments. ${ }^{\star} P<0.05$ S-phase of GFP-M IEC in comparison with untransfected control IEC cells. 
(a)

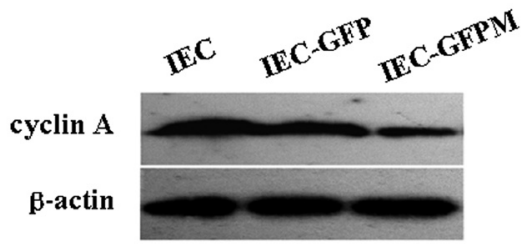

(b)

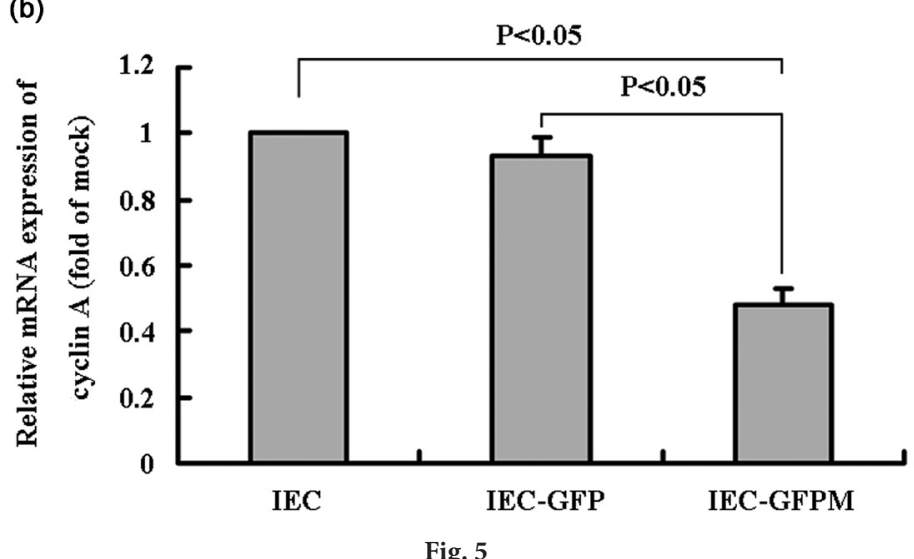

The expression level of cyclin A in PEDV M expressing IEC

(a) Western blot analysis of cyclin A expression level in GFP and GFP-M expressing cells and control IEC cells. $\beta$-actin was used as an internal control. (b) Relative mRNA expression of cyclin A detected by real-time qPCR in GFP and GFP-M expressing cells and control IEC cells. PCR results were normalized to the corresponding CT values for porcine $\beta$-actin mRNA. The results are mean \pm SD from three independent experiments.

(a)
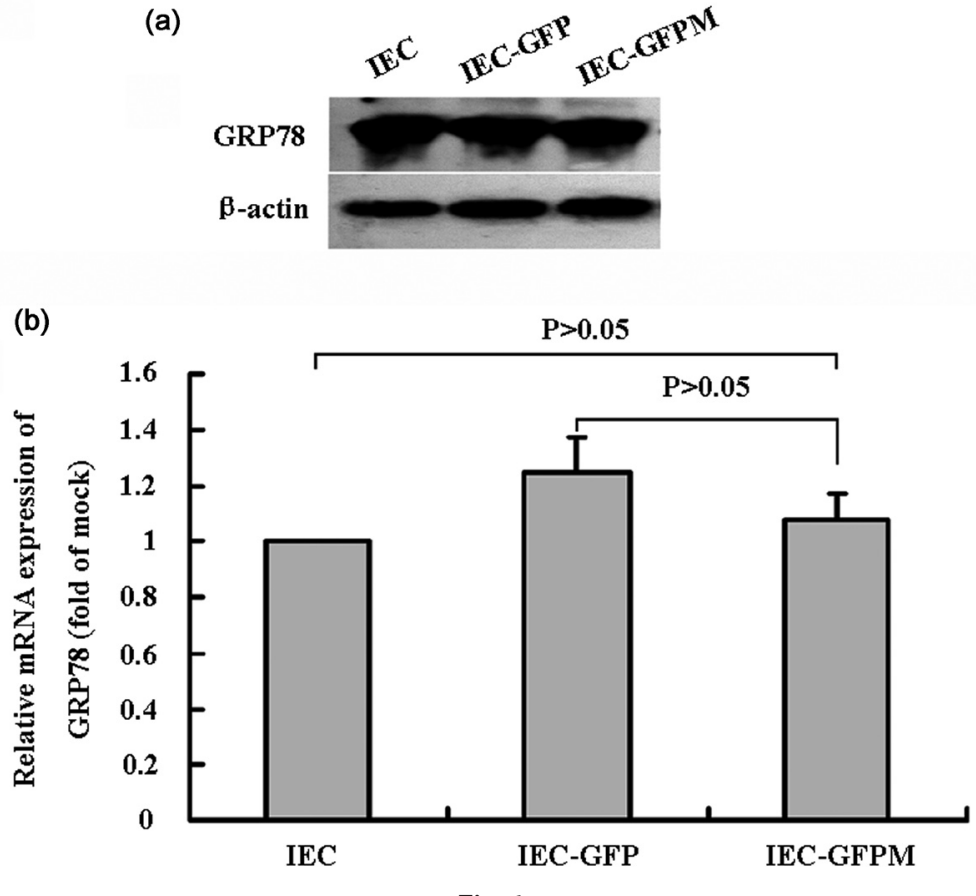

Fig. 6

The expression level of GRP78 in PEDV M expressing IEC

(a) Western blot analysis of GRP78 expression level in GFP and GFP-M expressing cells and control IEC cells. $\beta$-actin was used as an internal control. (b) Relative mRNA expression of GRP78 detected by real-time qPCR in GFP and GFP-M expressing cells and control IEC cells. PCR results were normalized to the corresponding $\mathrm{CT}$ values for porcine $\beta$-actin mRNA. The results are mean \pm SD from three independent experiments. 
cells (Fig. 6a). Moreover, in a real-time qPCR, the level of GRP78 transcription had no change in GFP-M-expressing cells compared to controls (Fig. 6b). The results suggest that PEDV M protein could not cause the induction of ER stress. Analysis of the activity of NF- $\kappa$ B in GFP-M-expressing cells demonstrates that NF- $\kappa B$ was not activated compared to control cells (Fig. 7). Taken together, our results revealed that PEDV M protein did not cause ER stress.

\section{PEDV M protein has no effect on IL-8 expression}

IL- 8 expression is regulated by activation of NF- $\kappa \mathrm{B}$ and the activation of NF- $\mathrm{KB}$ is associated with ER stress during the viral infection (Hoffmann et al., 2002; Waris et al., 2002). The secretion of IL- 8 in the supernatant of the untransfected cells and transfected cells was examined by using ELISA. As shown in Fig. 8a, the cells expressing GFP-M had no effect

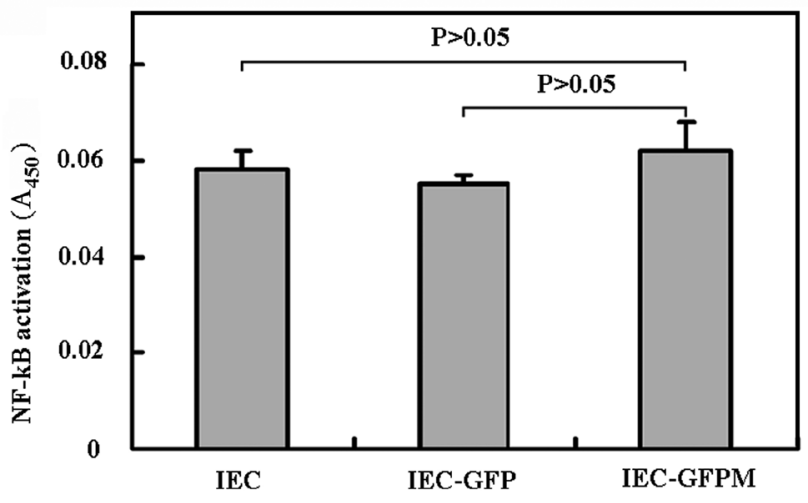

Fig. 7

Effect on NF- $\kappa B$ activity in PEDV $M$ expressing IECs NF- $\mathrm{B}$ p 65 activation was determined by the TransAM assay. The data represent the mean and standard deviation from three different experiments.
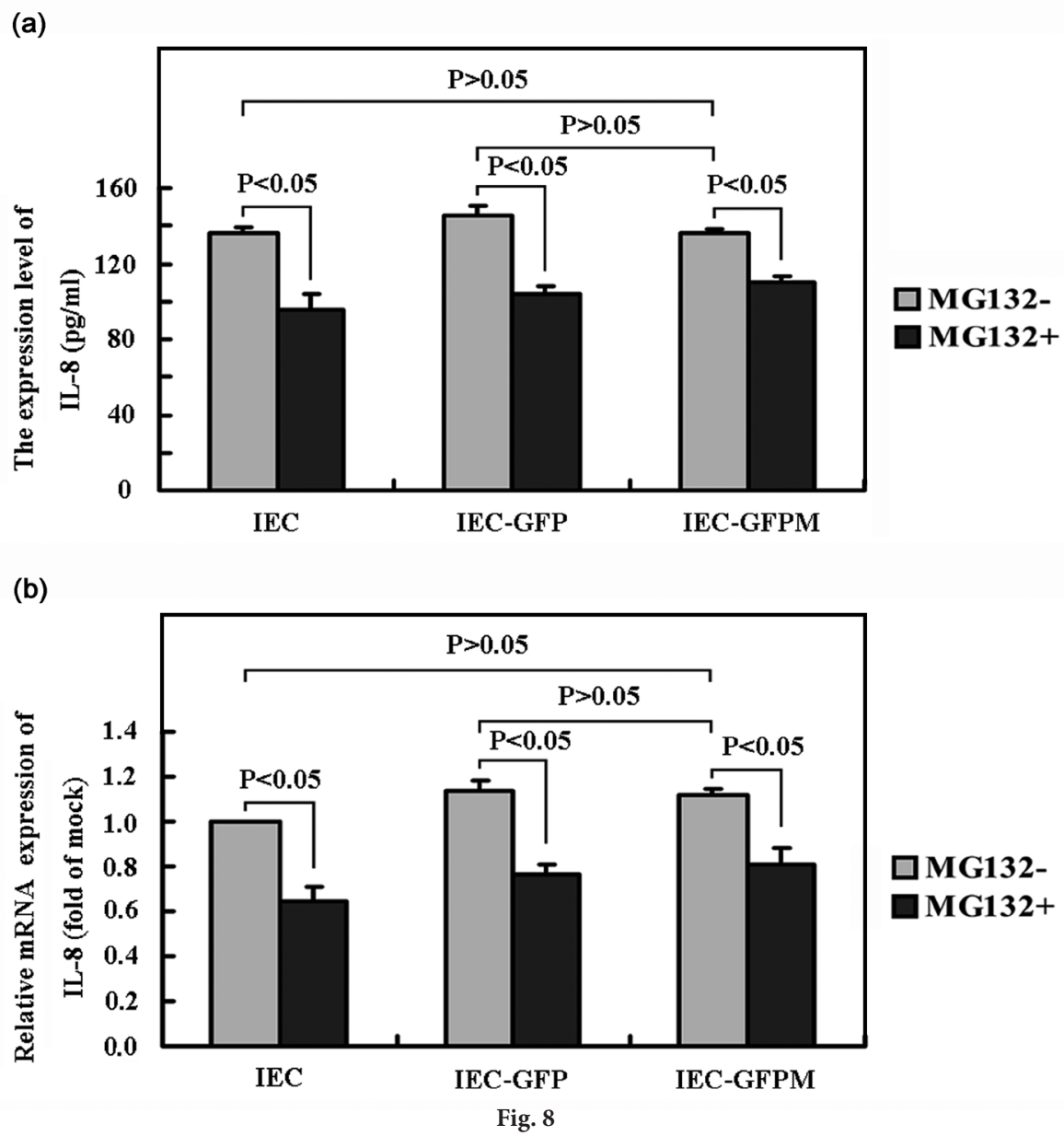

The expression level of IL-8 in PEDV M expressing IEC

To determine the level of IL-8, GFP and GFP-M expressing IEC and control IEC cells treated or untreated with MG132 were subjected to (a) ELISA and (b) real-time qPCR. The IL- 8 mRNA levels detected by real time RT-PCR were analyzed and normalized to the corresponding CT value of porcine $\beta$-actin mRNA. The data represent the mean and standard deviation from three different experiments. 


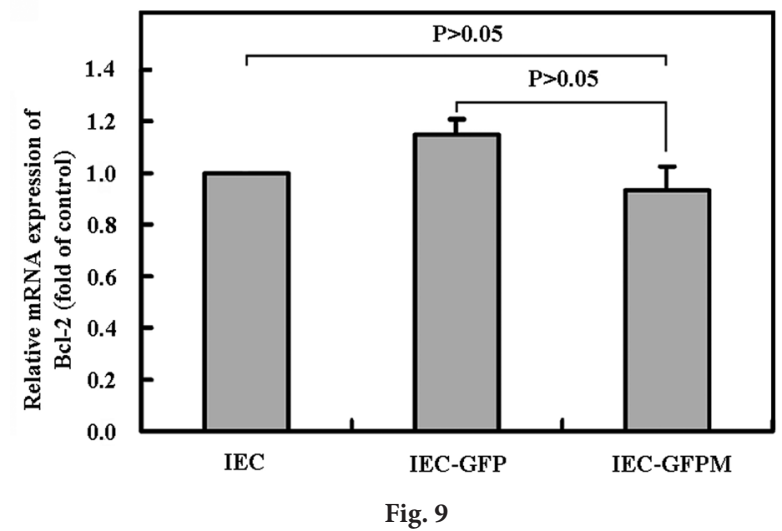

The Bcl-2 expression level in PEDV M expressing IEC Detection of Bcl-2 mRNA level in GFP and GFP-M expressing IEC and control IEC cells. The Bcl-2 mRNA levels were normalized to the corresponding CT value for porcine $\beta$-actin mRNA. The data represent the mean and standard deviation from three different experiments.

on IL-8 expression compared to control cells expressing GFP and untransfected cells. After the treatment with MG132, expression of IL-8 in GFP-M cells significantly decreased similarly to control cells. In comparison with control cells, an investigation of the transcriptional levels of IL- 8 by real-time qPCR revealed that the mRNA level of IL- 8 does not change in cells that express $M$ protein (Fig. 8b). These results suggest that PEDV $M$ protein has no effect on IL-8 expression in IEC.

\section{PEDV M protein does not affect $B c l-2$ expression}

It is well-known that the anti-apoptotic molecule Bcl-2 is tightly regulated by the transcription factor NF- $\kappa \mathrm{B}$ (Fahy et al., 2005). By employing real-time qPCR we showed that $\mathrm{Bcl}-2$ expression is not affected in the GFP-M expressing cells compared with that in control cells (Fig. 9).

\section{Discussion}

In recent years, many studies focused on the gene sequence analysis of PEDV. The genetic and phylogenetic analyses based on the $\mathrm{S}$ and $\mathrm{M}$ genes have been used to determine the relatedness of PEDV isolates (Chen et al., 2011; Junwei et al., 2006; Park et al., 2012; Yeo et al., 2003). However, the subcellular localization and function of PEDV $\mathrm{M}$ protein remains unclear. Also, the function of this protein is yet to be determined, particularly with regard to its effect on host cell physiological changes. In this study we have constructed eukaryotic expression vector and generated cell lines stably expressing the PEDV $\mathrm{M}$ in fusion with the GFP protein. Co-localization studies showed that GFP-M is localized in the whole cell. In the present study, the effect of PEDV M protein on IEC proliferation was also determined. This work provides evidence for the first time that the $M$ protein is capable of influencing cell proliferation and inducing cell cycle arrest at $\mathrm{S}$-phase. Cell cycle progression is regulated by the cyclin/Cdk complex activation. Cyclin A is very important to cells when switching from $S$ phase to $G 2 / M$ phase. Previous reports showed that cyclin A/Cdk2 has role in $S$ phase progression and regulates the timing of cyclin B/Cdk1 activation and entry into mitosis (Oakes et al., 2014). Data obtained from our Western blot analysis suggest that cyclin A protein level in cells expressing PEDV M protein is significantly lower than that in control cells. Furthermore, this study also revealed that the $M$ protein significantly inhibits the transcription of cyclin A. This suggests that the $\mathrm{M}$ protein of PEDV plays an important role, not only in regulation of the expression level of cyclin A protein but also in regulation of the transcription of cyclin A.

The ER has essential roles in multiple cellular processes that are required for normal cellular functions and cell survival (Anelli and Sitia, 2008). Although our results revealed that the $M$ protein is localized in the whole cell, we did not prove that the PEDV M protein induces ER stress, as showed by real-time qPCR and Western blot analysis of GRP78, a typical marker of ER stress. Interestingly, recent reports from our team demonstrated that both $\mathrm{N}$ and $\mathrm{E}$ proteins of PEDV can induce ER stress via upregulation of IL- 8 and activation of NF- $\kappa B$ (Xu et al., 2013a,b). Because viruses use the ER as an integral part of their replication strategy, they must contend with the ER stress response and the downstream consequences of ER stress signaling, including the initiation of an inflammatory response via the activation of NF-kB (Todd et al., 2008; Waris et al., 2002; Zhang and Kaufman, 2008). IL-8 plays an important role in the promotion of cell survival signaling and antagonizes the anti-viral activities of interferon. In this study, regulation of expression of IL- 8 and activation of NF- $\kappa B$ were not seen in IEC.

$\mathrm{NF}-\kappa \mathrm{B}$, a transcription factor, controls the expression of a variety of genes involved in innate and adaptive immunity and in cell survival (Geng et al., 2009; Li and Verma, 2002; Wietek and O'Neill, 2007). As we know, Bcl-2 has been shown to be an anti-apoptotic molecule which is associated with cell survival (Batsi et al., 2009; Ricca et al., 2000; Seo et al., 2009). A previous study suggested that the expression of $\mathrm{Bcl}-2$ is regulated by the NF- $\kappa \mathrm{B}$ (Fahy et al., 2005). However, in this study, the there was no significant change in expression level of $\mathrm{Bcl}-2$ in PEDV M protein expressing cells, suggesting that this protein may not play role in protecting the host cells from functional damage or apoptosis.

In the present study, our results revealed that the PEDV $\mathrm{M}$ protein is localized in the whole cell. It affects the IEC growth and induces cell cycle arrest at S-phase. The cell cycle 
arrest in the S-phase is associated with a decrease in cyclin A transcription level. The M protein does not cause ER stress nor alters IL-8 and Bcl-2 expression levels in IEC. Thus, the data suggest that PEDV M protein may not play an important role in the inflammatory response. This study provides evidence for function of PEDV M protein which is likely to be useful in understanding of PEDV pathogenesis.

Acknowledgements. This work was supported by grants from the basic research and operating expenses of Northwest A\&F University (Grant No. QN201201).

\section{References}

Anelli T, Sitia R (2008): Protein quality control in the early secretory pathway. EMBO J. 27, 315-327. http://dx.doi.org/10.1038/ sj.emboj. 7601974

Batsi C, Markopoulou S, Kontargiris E, Charalambous C, Thomas C, Christoforidis S, Kanavaros P, Constantinou AI, Marcu KB, Kolettas E (2009): Bcl-2 blocks 2-methoxyestradiol induced leukemia cell apoptosis by a $27 \mathrm{Kip} 1$-dependent G1/S cell cycle arrest in conjunction with NF- $\kappa \mathrm{B}$ activation. Biochem. Pharmacol. 78, 33-44. http://dx.doi. org/10.1016/j.bcp.2009.03.017

Bridgen A, Kocherhans R, Tobler K, Carvajal A, Ackermann M (1998): Further analysis of the genome of porcine epidemic diarrhoea virus. Adv. Experiment Med. Biol. 440, 781-786. http://dx.doi.org/10.1007/978-1-46155331-1 101

Chen J, Wang C, Shi H, Qiu HJ, Liu S, Shi D, Zhang X, Feng L (2011): Complete genome sequence of a Chinese virulent porcine epidemic diarrhea virus strain. J. Virol. 85, 11538-11539. http://dx.doi.org/10.1128/JVI.06024-11

Chulu JL, Huang WR, Wang L, Shih WL, Liu HJ (2010): Avian reovirus nonstructural protein $\mathrm{p} 17$-induced $\mathrm{G}(2) / \mathrm{M}$ cell cycle arrest and host cellular protein translation shutoff involve activation of p53-dependent pathways. J. Virol. 84, 7683-7694. http://dx.doi.org/10.1128/JVI.02604-09

Ducatelle R, Coussement W, Pensaert MB, Debouck P, Hoorens J (1981): In vivo morphogenesis of a new porcine enteric coronavirus, CV 777. Arch. Virol. 68, 35-44. http://dx.doi. org/10.1007/BF01315165

Egberink HF, Ederveen J, Callebaut P, Horzinek MC (1988): Characterization of the structural proteins of porcine epizootic diarrhea virus, strain CV777. Am. J. Vet. Res. $49,1320-1324$

Fahy BN, Schlieman MG, Mortenson MM, Virudachalam S, Bold RJ (2005): Targeting BCL-2 overexpression in various human malignancies through NF- $\mathrm{kB}$ inhibition by the proteasome inhibitor bortezomib. Cancer Chemother. Pharmacol. 56, 46-54. http://dx.doi.org/10.1007/s00280004-0944-5

Geng H, Wittwer T, Dittrich-Breiho O, Kracht M, Schmitz ML

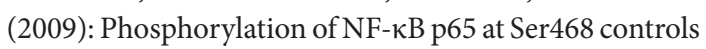
its COMMD1-dependent ubiquitination and target gene- specific proteasomal elimination. EMBO Reports 10, 381-386. http://dx.doi.org/10.1038/embor.2009.10

Hoffmann E, Dittrich-Breiholz O, Holtmann H, Kracht M (2002): Multiple control of interleukin-8 gene expression. J. Leukoc. Biol. 72, 847-855.

Hong M (2005): Transcriptional regulation of the Grp78 promoter by endoplasmic reticulum stress: role of TFII-I and its tyrosine phosphorylation. Biol. Chem. 280, 16821-16828. http://dx.doi.org/10.1074/jbc.M413753200

Honglei Z, Jie D, Yabing L, Xingang X, Dewen T (2012): RT-PCR Identification of porcine epidemic diarrhea virus and sequence analysis of its $\mathrm{M}, \mathrm{N}$ and $\mathrm{E}$ gene. Acta Agricult. Boreali-Occidentalis Sin. 21, 24-28.

Jing W, Yanming Z, Gang T, Fangning L, Hongchao Z, Lei H, Xiaoyun Y, Yanzhao X, Haixia H (2010): The isolation and identification of neonatal swine intestinal epithelial cells. Acta Vet. Zoo. Sin. 41, 92-98.

Junwei G, Baoxian L, Lijie T, Yijing L (2006): Cloning and sequence analysis of the $\mathrm{N}$ gene of porcine epidemic diarrhea virus LJB/03. Virus Genes 33, 215-219. http://dx.doi. org/10.1007/s11262-005-0059-Z

Ke GM, Chen HL, Ke LY, Ji WT, Chulu JL, Liao MH, Chang TJ, Liu HJ (2006): Development of a quantitative Light Cycler real-time RT-PCR for detection of avian reovirus. J. Virol. Methods 133, 6-13. http://dx.doi.org/10.1016/j. jviromet.2005.09.011

Kocherhans R, Bridgen A, Ackermann M, Tobler K (2001): Completion of the porcine epidemic diarrhoea coronavirus (PEDV) genome sequence. Virus Genes 23, 137-144. http://dx.doi.org/10.1023/A:1011831902219

Laude H, Gelfi J, Lavenant L, Charley B (1992): Single amino acid changes in the viral glycoprotein $\mathrm{M}$ affect induction of alpha interferon by the coronavirus transmissible gastroenteritis virus. J. Virol. 66, 743-749.

Li J, Ni M, Lee B, Barron E, Hinton DR, Lee AS (2008): The unfolded protein response regulator $\mathrm{GRP} 78 / \mathrm{BiP}$ is required for endoplasmic reticulum integrity and stress-induced autophagy in mammalian cells. Cell Death Differ. 15, 1460-1471. http://dx.doi.org/10.1038/cdd.2008.81

Li Q, Verma IM (2002): NF- $\kappa B$ regulation in the immune system. Nature Rev. Immun. 2, 725-734. http://dx.doi. org $/ 10.1038 /$ nri910

Liu HJ, Lin PY, Lee JW, Hsu HY and WL Shih (2005): Retardation of cell growth by avian reovirus p17 through the activation of p53 pathway. Biochem. Biophys. Res. Commun. 336, 709-715. http://dx.doi.org/10.1016/j.bbrc.2005.08.149

Livak KJ, Schmittgen TD (2001): Analysis of relative gene expression data using real-time quantitative PCR and the 2- $\Delta \Delta$ CT method. Methods 25, 402-408. http://dx.doi. org/10.1006/meth.2001.1262

Locker JK, Rose JK, Horzinek MC, Rottier PJ (1992): Membrane assembly of the triple-spanning coronavirus $\mathrm{M}$ protein. Individual transmembrane domains show preferred orientation. J. Biol. Chem. 267, 21911-21918.

Luppi F, Longo AM, de Boer WI, Rabe KF, Hiemstra PS (2007): Interleukin-8 stimulates cell proliferation in non-small cell lung cancer through epidermal growth factor recep- 
tor transactivation. Lung Cancer 56, 25-33. http://dx.doi. org/10.1016/j.lungcan.2006.11.014

Matsuo Y, Sawai H, Ochi N, Yasuda A, Sakamoto M, Takahashi H, Funahashi H, Takeyama H and S Guha (2009): Proteasome inhibitor MG132 inhibits angiogenesis in pancreatic cancer by blocking NF-кB activity. Dig. Dis. Sci. 55, 1167-1176.

Oakes V, Wang W, Harrington B, Lee WJ, Beamish H, Chia KM, Pinder A, Goto H, Inagaki M, Pavey S, Gabrielli B (2004): Cyclina/Cdk2 regulates Cdh1 and claspin during late S/G2 phase of the cell cycle. Cell Cycle 13, 3302-3311. http://dx.doi.org/10.4161/15384101.2014.949111

Park SJ, Kim HK, Song DS, An DJ, Park BK (2012): Complete genome sequences of a Korean virulent porcine epidemic diarrhea virus and its attenuated counterpart. J. Virol. 86, 5964-5964. http://dx.doi.org/10.1128/JVI.00557-12

Quinones QJ, de Ridder GG, Pizzo sv (2008): GRP78: a chaperone with diverse roles beyond the endoplasmic reticulum. Histol. Histopathol. 23, 1409-1416.

Ricca A, Biroccio A, Del Bufalo D, Mackay AR, Santoni A, Cippitelli M (2000): Bcl-2 over-expression enhances NFkappaB activity and induces mmp- 9 transcription in human MCF7(ADR) breast-cancer cells. Int. J. Cancer 86, 188-196. http://dx.doi.org/10.1002/(SICI)1097-0215(20000415)86:2<188::AID-IJC7>3.0.CO;2-W

Schierack P, Nordhoff M, Pollmann M, Weyrauch KD, Amasheh S, Lodemann U, Jores J, Tachu B, Kleta S, Blikslager A, Tedin K, Wieler LH (2005): Characterization of a porcine intestinal epithelial cell line for in vitro studies of microbial pathogenesis in swine. Histochem. Cell. Biol. 125, 293-305. http://dx.doi.org/10.1007/s00418-005-0067-Z

Seo M, Nam H-J, Kim S-Y, Juhnn Y-S (2009): Inhibitory heterotrimeric GTP-binding proteins inhibit hydrogen peroxide-induced apoptosis by up-regulation of Bcl-2 via NF-kB in H1299 human lung cancer cells. Biochem. Biophys. Res. Com. 381, 153-158. http://dx.doi.org/10.1016/j.bbrc.2009.01.188

Song D, Park B (2012): Porcine epidemic diarrhoea virus: a comprehensive review of molecular epidemiology, diagnosis, and vaccines. Virus Genes 44, 167-175. http://dx.doi. org/10.1007/s11262-012-0713-1
Tang Q-h, Zhang Y-m, Fan L, Tong G, He L, Dai C (2010): Classic swine fever virus NS2 protein leads to the induction of cell cycle arrest at S-phase and endoplasmic reticulum stress. Virol. J. 7, 4. http://dx.doi.org/10.1186/1743-422X-7-4

Todd DJ, Lee A-H, Glimcher LH (2008): The endoplasmic reticulum stress response in immunity and autoimmunity. Nat. Rev. Immunol. 8, 663-674. http://dx.doi.org/10.1038/nri2359

Wang K, Lu W, Chen J, Xie S, Shi H, Hsu H, Yu W, Xu K, Bian C, Fischer WB, Schwarz W, Feng L, Sun B (2012): PEDV ORF3 encodes an ion channel protein and regulates virus production. FEBS Letters 586, 384-391. http://dx.doi. org/10.1016/j.febslet.2012.01.005

Waris G, Tardif KD, Siddiqui A (2002): Endoplasmic reticulum (ER) stress: hepatitis $\mathrm{C}$ virus induces an ER-nucleus signal transduction pathway and activates NF-kappaB and STAT-3. Biochem. Pharmacol. 64, 1425-1430. http:// dx.doi.org/10.1016/S0006-2952(02)01300-X

Waugh DJ, Wilson C (2008): The interleukin-8 pathway in cancer. Clin. Cancer Res. 14, 6735-6741. http://dx.doi. org/10.1158/1078-0432.CCR-07-4843

Wietek C, O'Neill LAJ (2007): Diversity and regulation in the NF- $\kappa B$ system. Trends Biochem. Sci. 32, 311-319. http://dx.doi. org/10.1016/j.tibs.2007.05.003

Xu X, Zhang H, Zhang Q, Dong J, Liang Y, Huang Y, Liu HJ, Tong D (2013a): Porcine epidemic diarrhea virus E protein causes endoplasmic reticulum stress and up-regulates interleukin-8 expression. Virol. J. 10, 26. http://dx.doi. org/10.1186/1743-422X-10-26

Xu X, Zhang H, Zhang Q, Huang Y, Dong J, Liang Y, Liu H-J, Tong D (2013b): Porcine epidemic diarrhea virus $N$ protein prolongs S-phase cell cycle, induces endoplasmic reticulum stress, and up-regulates interleukin-8 expression. Ve.t Microb. 164, 212-221.

Yeo SG, Hernandez M, Krell PJ, Nagy EE (2003): Cloning and sequence analysis of the spike gene of porcine epidemic diarrhea virus Chinju99. Virus Genes 26, 239-246. http:// dx.doi.org/10.1023/A:1024443112717

Zhang K, Kaufman RJ (2008): From endoplasmic-reticulum stress to the inflammatory response. Nature 454, 455-462. http://dx.doi.org/10.1038/nature07203 